\title{
educação

\section{A aprendizagem do pensar e a impossibilidade de ensinar filosofia}

\author{
Daniel Rodrigues Ramos ${ }^{1}$ \\ Universidade Federal do Recôncavo da Bahia, Brasil
}

\begin{abstract}
Numa abordagem fenomenológica, o artigo reflete o ensino da Filosofia, assumindo-o como possível enquanto experiência da aprendizagem do pensar. Nesta direção, o estudo possui por meta mostrar que a compreensão desta possibilidade se radica em uma impossibilidade de caráter ontológico, uma vez que o aprender a pensar não pode ser ofertado ou possibilitado por outrem. Tal impossibilidade é reconduzida para o modo de constituição da singularidade humana. Neste horizonte, a (im) possibilidade de aprender a pensar funda-se no questionamento filosófico, porém, entendido como responsabilidade do ser humano por decidirse e apropriar-se de seu originário modo de ser. Para demonstrar esta fundamentação, o estudo parte do sentido ontológico de impossibilidade para o existir humano, definindo-a como remissão e salto para o possível, no caso, para o ser capaz do pensar e questionar. Em seguida, aclara-se o questionamento e seu caráter histórico, diferenciando-o do método de problematização das ciências positivas. Por fim, posiciona-se criticamente em relação às tendências dominantes em que se compreende o ensino da filosofia a partir das metas e dos métodos tecno-científicos, bem como da pedagogização do filosofar e, ainda, da sua burocratização em vista de seu enquadramento aos mecanismos institucionais de produção do conhecimento científico com suas atuais exigências.
\end{abstract}

Palavras-chave: Pensamento; Questionamento; Ciência e técnica; Ensino da filosofia; Pedagogização

\section{IN T RODUÇ ÃO}

O ser humano é ao modo de uma abertura, que se instaura e se amplia vigorosamente, alargando sempre mais os limites de seu mundo. Ele o é, certamente, em virtude do pensamento. Disto bem se sabe, hoje, mediante a amplitude ilimitada de poder que a humanidade moderna julga ter por meio do conhecimento científico e técnico. "Somente contra a morte [o ser humano] clamará em vão por um socorro, embora saiba fugir até de males intratáveis" (Sófocles, 2004, p. 215), diz o verso de um dos coros da tragédia Antígona. Contudo, talvez nem da morte ele tenha verdadeiro temor, hodiernamente, pois, com o poder que o conhecimento técnico-científico lhe confere, insulta até a própria morte e faz dela algo infame. Com tantos recursos para prolongar a existência, possibilitados pelo 
extraordinário desenvolvimento da ciência, ele se tornou o senhor do viver e do morrer.

Mas nem sempre foi assim. Nem precisa continuar a sê-lo. Não obstante, no momento, tudo que é fundamental terá que persistir, por tempo indeterminado, sob o interesse de domínio exercido, em especial, por meio do conhecimento técnico-científico. É o que acontece com as produções criativas do espírito, como o pensamento ou, mais precisamente, com a filosofia que se veste com as aparências de pensamento, fora e dentro dos estabelecimentos de ensino. Por toda a parte, vigora um esvaziamento das forças criativas do espírito, uma despotenciação que lhe retira a profundidade, na medida em que, progressivamente, substituem-se os poderes da criação pelo poder de analisar e examinar (criticamente) coisas já postas, com vista a transformá-las e reproduzi-las em massa (Heidegger, 1999a). É deste modo que o pensamento, reduzido à capacidade de explicação racional, inteligência ordenadora e, por fim, engenho inventivo, tantas vezes é subjugado como instrumento de ensino e aprendizagem, em vez de aprendido desde uma originária experiência de sua essência criadora. Contudo, o pensamento é vigor impetuoso. Estranho é querer domá-lo no âmbito da filosofia e domesticá-lo no exercício profissional dos filósofos. Certamente por razão desta criatividade indomável, o verdadeiro pensamento, parafraseando Pascal (2005), sempre zomba da filosofia (que não seja autêntico filosofar) e de todo e qualquer conhecimento sem experiência da verdade. Mas "zombar da filosofia é verdadeiramente filosofar" (Pascal, 2005, p. 237). Assim, porque é indômito, o pensamento, desde muito, zomba da filosofia que pretende esconder sua indigência com os engenhos da inteligência calculadora. $\mathrm{O}$ pensar não sucumbe definitivamente a qualquer forma de cálculo de verdades, por meio das quais se impõe o domínio e se intensifica o poder do conhecer em vista do mero produzir.

Ora, é neste contexto de perda do vigor das forças do espírito que o pensamento está muito além e distante dos cursos de filosofia, que, na maioria das vezes, oscilam entre os métodos e os problemas da ciência historiográfica e os das ciências didático-pedagógicas. Mas isto não é só um mal hodierno. Parece ser, muito mais, uma contenda inscrita na história e essência do pensamento. Já na sua origem, no vigor de instauração de sua história, o pensamento ultrapassou os limites da filosofia, pois, ao antecipá-la, fez-se primeiramente presente na figura do mito e da arte. Assim, não é para admirar que hoje, no final desta história, suponha-se, com fé inquebrantável, que a força criativa do pensamento possa ser subjugada pelo poder de objetivação e pretensões utilitárias da ciência e da técnica, mas também pelas políticas de planejamento e fomento da cultura e redistribuição equitativa dos produtos culturais, por exemplo, via educação. É uma situação, porém, digna de espanto.

Tendo em consideração esta situação histórica como fundo da reflexão, o problema da presente discussão, de início, pode ser colocado de modo zombeteiro: texto, palavras, teses, filosofemas, regras lógicas e de rigor de argumentação, enfim, tudo com o que é necessário se habituar e (se) entender com muita dificuldade no ensino e na aprendizagem de filosofia é apenas o pó, vestígios da experiência do pensar. Os pensadores a sepultam consigo no túmulo do esquecimento. Para trás, ficam apenas as suas obras, resquícios de um esforço hercúleo no embate com a tarefa do pensamento. Na letra morta, porém, são apenas poeira; na força do espírito criativo, da qual elas são vestígios, elas são, porém, sinalização de um tortuoso caminho a ser percorrido na experiência de 
aprender a pensar. Assim, o único modo de manter viva a tradição filosófica é repetindo esta experiência de maneira inusitada e singular. Nesta direção, parece ir o testemunho de Platão (1999), no Fédon (96a-98b), segundo o qual as obras dos pensadores, suas ideias, argumentos e tudo o mais com que se lida na aprendizagem da filosofia não são mais do que pó:

$\mathrm{Na}$ minha juventude sentia um desejo irresistível de aprender esse gênero de sabedoria

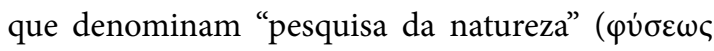

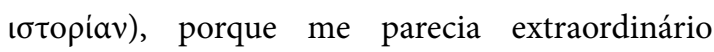
conhecer a causa de cada coisa, o que a faz nascer, e não havia trabalho que não quisesse analisar... $\mathrm{E}$ acabei por adquirir a convicção, por causas destas pesquisas, de que eu era de uma inabilidade digna de nota!... Decidi adotar outro método porque aquele não me satisfazia. Havendo ouvido alguém dizer que lera num livro de Anaxágoras que o espírito (voüs) era a causa e a regra de todos os seres, espantei-me. Pareceu-me extraordinário que a inteligência (o espírito), havendo criado todas as coisas, as havia disposto da melhor forma... Sentiame feliz por haver encontrado um mestre como Anaxágoras, que me explicaria as causas de todas as coisas... Porque não podia conceber que, após ter afirmado que a inteligência (o espírito) os havia criado, pudesse dar-me ele outra causa além dessa que é a melhor e que serve a cada uma, bem como ao conjunto. E senti esperança de que após haver-me ensinado esta causa, em geral e em particular, me ensinasse em que consiste o bem de cada coisa, em geral e em particular. Não teria trocado esta minha esperança por nada. Peguei seus livros com enorme entusiasmo e os li com grande atenção e rapidez, para saber o quanto antes do melhor e do pior de todas as coisas. Porém, assim que li um pouco, vi frustradas estas esperanças, vi que... Anaxágoras não dava razão alguma a ordem das coisas, e que o espírito era substituído pelo ar, éter, a água e outras coisas absurda... Eu almejaria ser discípulo de qualquer homem que houvesse podido me ensinar a causa, mas como não posso chegar a conhecê-la, nem por mim nem por outro, desejas, Cebes, que te conte a tentativa que fez para encontrá-la?. (pp. $218-221)^{1}$

Deste testemunho emerge uma perplexidade que dá que pensar: não é possível ensinar filosofia! Esta negação nomeia, pois, uma impossibilidade, que diz não estar em nosso poder dar ao outro a possibilidade de aprender a pensar. Se não pode ser ensinado, o pensar também não pode ser objeto de estudo e, portanto, não se estuda filosofia tal como se estuda tantas outras disciplinas que compõem o currículo escolar. Pensar, contudo, é o núcleo vivo da filosofia. Sem uma autêntica experiência do pensar não se aprende a filosofar. Mas, se pensar não se adquire nem pela via dos processos de ensino, sejam eles formais ou informais, nem pelos instrumentos e métodos de estudo, não está em poder dos seres humanos nem das instituições ensinar a filosofia e, no entanto, nisto tudo ainda se pode abrir acesso ao pensar. De repente, no seio desta impossibilidade, mediante o ensino de filosofia, avista-se um caminho por se fazer para e no pensamento. Na base deste paradoxo, o ensino de filosofia repousa sobre uma fundamental impossibilidade. Aclarar em que sentido esta impossibilidade particular ao ensino de filosofia deve ser compreendida é o que guia a presente reflexão.

$\begin{array}{lccr}\text { 1. COMO } & \text { ENTENDER } & \text { A } \\ \text { IMPOSSIBILIDADE } & \text { DE } & \text { ENSINAR } \\ \text { FILOSOFIA? } & & \end{array}$

Sem a pretensão de oferecer um último esclarecimento, é preciso indicar em que

\footnotetext{
${ }^{1}$ Tradução ligeiramente modificada a partir da comparação com o texto grego e com a tradução italiana (Platone, 2005). O grifo é do autor.
} 
direção se entende a impossibilidade acenada. De antemão, deve-se enfatizar que tal impossibilidade pertence à essência do filosofar. Por conseguinte, não deve ser tomada, sem mais, como justificativa para declarar que todos os esforços, iniciativas, instituições, políticas e tudo o mais que lida com o exercício do ensino de filosofia, ou possui sua razão de ser na produção do conhecimento filosófico, foram, são e serão inúteis e ineficazes. Quem assim fizesse, com certeza, nada teria entendido da impossibilidade em que repousa o ensino de filosofia. A impossibilidade em questão não é sinônima da ineficiência dos processos educacionais. Não se trata, pois, da ineficiência que deveria ser banida mediante o constante aperfeiçoamento e reformas dos sistemas educacionais, bem como pelo avanço das ciências da educação ou pela renovação das concepções teórico-pedagógicas acerca do ensino ou, ainda, pela qualificação dos agentes educativos envolvidos no ensino da filosofia e consequente aprimoramento das técnicas pedagógicas. Enfim, com o fato de não estar em nosso poder ensinar filosofia nada se alude aos problemas de funcionamento da burocracia institucional, nem à fragilidade da organização e concepção dos sistemas educativos, como também aos insucessos e vicissitudes dos agentes educativos envolvidos no ensino $\mathrm{e}$ aprendizagem da filosofia. As razões, os efeitos e as possíveis medidas corretivas de tudo isto são justos problemas, porém, somente na ordem do teórico-operacional.

Todas estas problematizações, por mais legítimas que sejam, do ponto de vista crítico das ciências pedagógicas ou de quaisquer outras que se ocupam com o acontecer educativo como objeto de estudo, não podem nem sequer pressentir tal impossibilidade qua impossibilidade. Nisto, pois, ainda se vê o filosofar na ótica dos mecanismos de produção e asseguração de resultados e não a partir das leis próprias do pensamento - enfim, porque, na maioria das vezes, vê-se o pensamento como cálculo de poder e de empoderamento do sujeito. Nesta ótica calculadora de efeitos, com razão, para o funcionamento e a manutenção da lógica da produção, qualquer impossibilidade é impedimento a ser excluído em vista do domínio e controle total do produto. Para tanto, deve-se assegurar inclusive as condições de possibilidade da produção, de controle. Consequentemente, todo o processo de produção é predefinido para endereçá-lo para um domínio sempre maior e mais amplo. Mas o pensar é busca sem endereço pré-estabelecido, senão o da própria busca. Aliás, uma busca que, na maioria das vezes, desconstrói o que já se produziu e, por fim, rigidamente se estabeleceu. Por conseguinte, nesta busca, produto não há, a não ser a formação da identidade humana. Neste "produto" ou "produção", porém, não se admite cálculo de resultados e, consequentemente, nenhuma deficiência. É o que se observa no testemunho de grandes pensadores, como Heidegger (1992a), a partir do qual se apreende que, na verdade, a deficiência pertence ao olhar que olha para a busca do pensar e, não compreendendo as suas leis internas, caracteriza-o como improdutivo:

Se o buscar deve ser a meta, então, não se estabelece como meta mesma a ausência sem fim de meta? Assim pensa o entendimento calculador. Se o buscar deve ser a meta, deste modo não se perpetua a irrequietação e a insatisfação? Assim julga o sentimento ávido de rápida posse. Reconhecemos que o buscar, cada vez, produz na existência (Dasein) a mais alta estabilidade e equilíbrio - com certeza, apenas quando este buscar busca em modo próprio (eigentlich), isto é, quando se estende mais amplamente no mais escondido (Verborgenste) e deixa para trás de si a mera curiosidade. (p. 5) 
Semelhante testemunho poderia ser retirado da busca da verdade empreendida por Agostinho. Com efeito, ele lembra que o maior perigo desta busca é aquele da curiositas (Agostinho, 2002), isto é, do ver por meramente conhecer, o querer tudo conhecer somente pelo prazer do ver superficial e disperso. Tal conhecer é aquele que corre avidamente atrás do que é belo, harmonioso, suave, enfim, do que é agradável aos sentidos, somente para vê-los e, sem demora, abandonálos, sem avistar e compreender o sentido oculto dos acontecimentos observados. Diríamos hoje: este ver é a busca indiscriminada por informação pelo prazer do somente tomar conhecimento a respeito de algo - e, se encontra o horrendo ou monstruoso, também experimenta o prazer de querer atualizar-se de novidades, inovações e toda a sorte de acontecimentos presentes. Em tal ver, busca-se algo que se pode encontrar somente fora da busca, por exemplo, um efeito eficaz ou a posse de um conhecimento. Nesta modalidade de busca, a existência humana se dispersa.

Para o que se tenta compreender nesta reflexão, porém, é importante notar que, se acontece experimentar uma impossibilidade sequer neste tipo de busca, ávida e irrequieta, de coisas meramente visíveis e metas factíveis, esta é mera negatividade. Pois é o tipo de impossibilidade que se interpõe como um obstáculo para o ver sem muita aprendizagem do olhar e para o gozo imediato com as coisas fáceis. É impedimento para acúmulo do conhecimento e, do ponto de vista da pragmática educativa, é bloqueio para um eficaz processo didático-pedagógico. É o ver, pois, que não inova, não age, não provoca mudanças sociais, etc. Na verdade, é tal modo de lidar com os obstáculos do saber que constitui denso bloqueio para a aprendizagem do pensar. Pois, desde o início da tradição filosófica, graças à paixão dos gregos pela aventura da aprendizagem da visão, pensar é um ver essencial. No habituarse ao desenvolvimento desta visão, no entanto, está a caminho a conquista ou a perda da natureza humana. Porque aprender a ver é aprender a ser (tornar-se) humano, pois somos os únicos entes capazes de apreender e estabelecer morada no Verborgenste, o mais oculto, como diria Heidegger (1992a). Aprender a ver o invisível, então, é a atividade peculiar do pensar, da nossa inclinação para saber a profundeza escondida das coisas. Certamente, era isto que Aristóteles

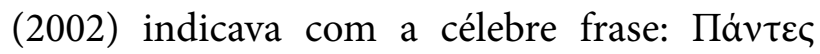

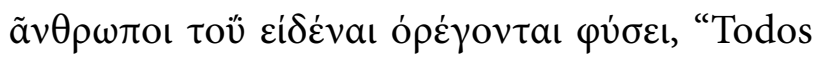
os homens, por saber, tendem ao saber" (Met 980a 20). Todos os homens tendem, no seu próprio ser, a ver essencialmente. Porém, para a conquista desta própria tendência, é necessário aprender a conviver com as impossibilidades que, somente para o ver mais imediato daquilo que está pronto e dado à mão para a posse, uso e prazer, são impedimentos e denso bloqueio à claridade da compreensão. Ultrapassar estas dificuldades, perceber que são meras aparências de impossibilidade, exige um caminho na aprendizagem do ver essencial.

Longo e árduo é este caminho, em razão do mais oculto. Este tem luminosidade e visibilidade próprias; pode cegar como a claridade do sol meridiano. Justamente por causa de seu modo específico de ser claro e evidente, não se deixa visualizar tão facilmente e escapa ao ver cuja intencionalidade é só a curiosidade do mero tomar conhecimento. Em todo o caso, deve-se reter que a impossibilidade pertence à essência da filosofia, mas esta pertinência vem à tona somente quando o filosofar se dá a partir das leis internas do pensar e compreendido desde a ótica de quem o julga difícil e quase impossível aprender a pensar. E isto não por falta de esforço, mas por já estar habituado ao empenho cotidiano da busca filosófica. Quanto mais hábil neste empenho, tanto mais o confronto com aquilo que não é automaticamente compreensível, com o não facilmente dizível nem prontamente reproduzível. Em questão, então, está uma impossibilidade que não é encontrada pela 
perspectiva de um sujeito observador, situado de fora do pensar, que o avalia a partir de metas estranhas e externas. Antes, vai-se ao encontro desta impossibilidade, quando o sujeito se dispõe a sofrer a força e a acolher as exigências de decisões fundamentais, as quais residem na experiência da aprendizagem do pensar, do ver capaz de conduzir o ser humano para si mesmo.

Ademais, é necessário enfatizar que a ideia de deficiência, tanto quanto a de ineficácia, não serve para caracterizar uma impossibilidade, sobretudo porque tal experiência de não-poder tem a ver com uma originária ação: a constituição da identidade humana a partir de diferentes condições de existência singular e histórica. Independentemente da inumerável gama destas determinações pessoais e epocais, a constituição da identidade humana é uma ação que joga sempre com as potencialidades fundamentais do ser humano para trazê-lo para si mesmo. E, no caso do ensino de filosofia, joga-se nada mais e nada menos com identidade humana que a tradição ocidental escolheu para designar o traço distintivo do humano, isto é, o pensamento. Em suma, a ideia de deficiência não é por si só válida para dizer o que significa impossibilidade para a condição humana, a partir de seu dinamismo ontológico e constituinte. Radicalmente, o problema não se situa no significado da ideia de impossibilidade como deficiência, impedimento a ser eliminado e outros significados mais, mas na própria origem da significação; a deficiência desta concepção está na absoluta inadequação para indicar o solo em que o não-poder da impossibilidade está plantado e para traduzir o dinamismo criativo que, a partir deste solo, este não-poder possibilita. Com efeito, neste horizonte ontológico-existencial, admitir a imediata equivalência entre impossibilidade e deficiência como válida somente é possível porque se está por demasiado acostumado, como alertou Heidegger (2008a) em seu célebre opúsculo sobre o humanismo, a conceber a essência de todo o agir como a produção de um efeito e a medir a efetividade pela utilidade dos resultados. Também o pensar e demais potencialidades do ser humano agir e consumar historicamente a sua própria essência não são subtraídas deste apelo que atinge o ser humano moderno no seu próprio ser. Sob o império da ciência e da técnica, com efeito, toda a humanidade, na unidade de sua identidade, é solicitada por uma interpelação, a saber, a de colocar as decisões e as ações mais essenciais no horizonte da produção de efeitos e tudo conceber na perspectiva da eficácia (Heidegger, 1972). As ciências e a técnica dominam e possuem controle em extensão planetária, não porque estão em toda parte ou porque se tornou impossível qualquer relação entre os seres humanos e as coisas que não seja mediada pela técnica, mas porque ela ameaça ser a única possibilidade de o ser humano pensar e curar da tarefa de se tornar, historicamente, ele mesmo. É daí que nascem, então, as diversas significações inadequadas de impossibilidade que, de um modo ou outro, denotam certa impotência no poderio do sujeito.

Assim, a impossibilidade parece ser excludente da possibilidade e todo o não-poder não seria mais que a deficiência da ilimitada vontade de poder e domínio. Todavia, as coisas são bem o contrário para a condição humana. De fato, para compreender o modo próprio do humano se tornar humano e pôr em obra as suas potencialidades, o impossível não pode ser idealisticamente medido como o irrealizável, como também não deve ser entendido, em modo lógico-abstrato, como sendo aquilo que anula a possibilidade. Isto vale unicamente para os produtos, instrumentos e tudo com o que os seres humanos se ocupam, visto que, sendo algo já dado e acabado, a impossibilidade é simplesmente o não efetível ou não factível, o prontamente inacessível. Em síntese, o impossível é aquilo que não está disponível para 
a aplicação, para a ocupação ou manipulação. Mas, para os humanos, a existência não é algo disponível nem indisponível (Heidegger, 2000). Antes, eles a possuem como a tarefa de realização ou a criação de si mesmos. Assim, o impossível também é uma possibilidade, em razão da tarefa de singularização ser a definição de um não-ser inerente ao próprio ser, isto é, tornar presente o que por enquanto não se é, mas que pertence essencialmente àquela possibilidade que por ora se é. Realizar-se é, pois, um jogo de ser e não ser, de poder e não poder ser. Pelo simples fato de os seres humanos serem finitos e mortais, inscreve-se um "não" na existência humana, pois o não-poder é constitutivo e inerente ao poderser. Assim, todo o não-poder que o ser humano experimenta a respeito de si mesmo é, na verdade, remissão para o que pode ser e realizar a partir de si e "fazer" com as suas potencialidades, seja esta remissão realizada de modo próprio ou impróprio.

Deste modo, o não-poder permite que o poder-ser se projete, aperfeiçoe e se consume. A impossibilidade é condição de possibilidade de finitização, de definição de si, haja vista que todo o ser, toda a realização, para o ser humano, é sempre realização de si como uma possibilidade inconclusa. O não-poder é reserva de possibilidades de ser e tornar a si mesmo, é futuro anunciado de uma possibilidade já presente. Então, impossibilidade é a força íntima e vigor do poder da possiblidade de um acontecimento singular da existência humana. Para a facticidade da existência, o não das impossibilidades, então, não é pura negação ou privação, mas algo essencialmente positivo. Em que sentido? $\mathrm{Na}$ perspectiva em que o impossível é aquilo que delimita a condição própria do ser humano existir e constantemente se (re)criar segundo sua possibilidade singular. A impossibilidade, assim, obriga o ser humano a saltar decididamente dentro do que é próprio e possível, assumindo-o decididamente. Não-poder isto ou aquilo, na condição originária da existência, não possui, pois, o valor de uma proposição negativa, mas de uma experiência, ao mesmo tempo, constritiva e criativa. A experiência da impossibilidade é, na verdade, a do único possível e, por isto, necessário.

Desta necessidade vive o pensar, sobretudo quando as forças do espírito humano vigoram em toda a sua potencialidade criativa. Se, então, agora, neste momento, não está em poder de alguém filosofar, no confronto com os pensamentos e obras dos pensadores, esta impossibilidade não está dada a ele como falta de posse de algo fora dele, algo incompreensível diante dele, mas como "algo" essencial de si, a ser apropriado pelo ensino e estudo da filosofia. A impossibilidade está nele mesmo, em seu ser, assinalando-o com a possibilidade ainda não consumada de já ser aquele ser capaz de perguntar e compreender o mais oculto, de si e de todas as coisas. A apropriação do pensamento, então, não vem por meio da posse do que ele não possui e, por isto, seria possível de ser dado por outrem, por aquele que ensina. Pelo contrário, ela acontece por meio do que já possui e constitui o ser humano, sua própria capacidade de pensar. Porque o ser humano precisa se tornar pleno em seu ser-capaz, ser hábil em pensar, não há outro caminho senão o exercício que, pouco a pouco, se torna afeição e gosto pelo pensar. Não há outro caminho senão o exercício que, pouco a pouco, se torna afeição e gosto pelo pensar.

Tudo isto quer dizer que o ser humano pode aprender a pensar, porque já é capaz de pensar; que pode aprender filosofia, porque, de algum modo, já mora na filosofia. É uma crassa ingenuidade crer que alguém aprende a filosofar porque um curso ou alguém lhe ensinou um conjunto de ideias e teorias complexas e abstratas a respeito do pensamento, com as quais se pode ocupar, no ensino ou no estudo da filosofia. De igual modo, é demasiadamente ingênuo crer que o pensamento seja mero resultado de um 
sujeito superdotado, inventivo e genial. Quando, então, se afirma que não é possível ensinar a filosofia, é preciso suspeitar que nesta afirmação, se compreendida no horizonte ontológicoexistencial, encontra-se a possibilidade mais própria de filosofar e acenar a outros, por meio do ensino, que o filosofar se coaduna, segundo seus próprios imperativos, com o modo pelo qual a existência humana se realiza. Aprender a pensar, então, não é informar-se a respeito do que pensaram os pensadores, para repeti-lo ou transformá-lo em formas reelaboradas, em vista de fornecer inovadoras contribuições ao conhecimento filosófico. Pensar não se define pelo inovar, pelo acréscimo de conhecimento - o que, de certo modo, é extremamente válido para as ciências -, mas antes tem a ver com a criação de nós mesmos. Assim, aprender a pensar é possibilidade de aprender a ser o que já somos, isto é, pensadores por natureza e identidade, mas que só se realiza no confronto de uma experiência bem-feita com a impossibilidade que ela guarda em si. Por esta razão, está em questão uma impossibilidade que não deve ser eliminada do acontecer educativo-formativo, mas, pelo contrário, experimentada em toda a sua radicalidade, pois na sua exclusão ou evitação não há essencial aprendizagem do pensar, não é algo que se doa nem que se recebe de outrem. Como, porém, se faz tal aprendizagem?

\section{IMPOSSIBILIDADE E QUESTIONA-} MENTO: A “INTERMEDIAÇÃO" DA QUESTÃO

Nas linhas supracitadas, na introdução, em que Platão relata o itinerário de sua busca filosófica, evidencia-se outra face da impossibilidade que se tenta acenar. Tais linhas mostram, com efeito, que o pensar e sua aprendizagem pertencem à questão mesma e, portanto, em modo fundamental, aprender a pensar não é um problema subjetivo do discente, nem de transmissão objetiva pela docência, nem de uma relação entre ambos. Segundo o testemunho do pensador, a aprendizagem do pensar é o fruto de sua busca de questionar sua questão, nos retrocessos e avanços da busca mesma. Contudo, é digno de nota que não há privilégio de nenhum polo, seja do mestre ou do aprendiz, mas o que vem à tona é justamente uma impossibilidade de delegar a aprendizagem do pensar a outro e, ao mesmo tempo, de assumi-la sem a convivência interhumana, isto é, de perfazê-la sozinho. Se fosse decisivo o último caso, o aprendiz seria aquele que inventa algo novo, sem passado e sem um saber radicalmente histórico. Entretanto, no testemunho de Platão, entrevê-se que a aprendizagem do pensar não se dá por mérito do esforço de um sujeito isolado. De outro lado, não resulta do ensino de outrem, pois, como no impasse experimentado por Platão, não foi possível a ele encontrar na busca do outro a resposta para a sua questão. $\mathrm{O}$ encontro com a questão é único para cada pensador, assim como são exclusivamente suas as respostas que daí surgem, pois o pensador é quem conquistou uma posição original e única na história do questionamento radical da verdade (Heidegger, 2010). Assim, a impossibilidade de ensinar filosofia aponta para o fato que filosofar não é aprendizagem de um dado objetivo, mas também não é um acontecimento subjetivo. Pensar não é individual nem coletivo; não é pura reprodução do já dito pelos pensadores e mestres, mas também não é mera invenção do aprendiz.

Com tais binômios se chega muito tarde para compreender que ensinar e aprender filosofia depende de como se mantém no medium da experiência da aprendizagem do pensar, isto é, junto àquilo que deve ser pensado e na correspondência ao que se impõe como digno de ser pensado ao longo da tarefa singular de cada pensador. Neste sentido, não é possível 
ensinar ou estudar a filosofia, porque nesta compreensão polarizada entre sujeito e objeto, docência e discente, mesmo quando se alardeia o valor da relação e da inter-relação dos polos, na maioria das vezes, o essencial está esquecido: a experiência de aprender a pensar é medial e inter-mediária. Como tal, é prévia a todas estas divisões e tentativas de reunir $a$ posteriori o que foi anteriormente dividido. É no âmbito destas questões que se dá o pensar. Mas a questão não é nenhum instrumento, nenhum problema meramente teórico, com o qual se pode ocupar, mas sim o medium mesmo, pois nesta experiência o caminho é a própria questão (Heidegger, 1999b); caminho que se abre tão somente na medida em que é questionada e ao longo do qual os pensadores se perfazem. O questionamento da questão, então, é o acontecimento que revela o dinamismo paradoxal da história do pensamento: a(s) mesma(s) coisa(s) por ser(em) pensada(s), porém, conforme o modo próprio de cada pensador se implicar com a questão, do que surge uma diversidade de posicionamentos reunidos na unidade de um só acontecimento. Deste modo, trata-se de um acontecimento essencialmente histórico, inevitavelmente remetido para as suas origens, mas, sobretudo, detentor de futuro indeterminado, para aquém e além de qualquer específico questionamento da questão. Assim, a questão é medium primordial do pensar. E sem o intermédio da questão, no fluxo de seu próprio questionamento não se desdobraria a história, nem surgiria a comum-unidade dos pensadores.

Nesta perspectiva histórica e fundamental, portanto, a questão é o lugar e a ambiência de uma convivência essencial, porque ela é responsável por gerar a unidade de reunião entre os que a pensam. A partir desta unidade, é apenas uma aparência o seguinte impasse: de um lado, é impossível reduzir o questionamento ao esforço subjetivo, embora custe ao pensador uma fadiga enorme para aprender e manter-se no filosofar; de outro lado, também não é redutível ao apossar-se de noções dos outros, sobretudo, quando este assenhorar-se está no interesse do empoderar que não se consome em favor do que se aprende. Antes, é a questão mesma que guia a busca de determinado pensador; é a iluminação repentina de um caminho que o obriga a não poder ser ele mesmo senão na obra de querer compreendê-la, até o fim, na trajetória de consumação da única possibilidade que esta iluminação oferece. Também a este respeito, Platão é mestre. Na sua VII Carta (341c), contra aqueles que ensinavam suas ideias e teses, repetindo somente aquilo que se ouviu do próprio Platão ou divulgando as suas descobertas como se fossem criação deles, ele afirma: "Não há e, tampouco, jamais haverá algum escrito de minha autoria que trate de tal coisa [que outros escreveram e repetiram], visto que não é passível de verbalização como outros estudos, mas, na condição de um produto de prolongada aplicação conjunta [de mestre e discípulo] é gerada na alma de súbito, como a luz que cintila quando uma fogueira é acesa, alimentando em seguida em si mesma" (Platão, 2011)2.

Porque a questão nos antecede, no passado e no futuro, nenhum pensador está sozinho.

\footnotetext{
${ }^{2} \mathrm{O}$ sentido desta afirmação se mostra com maior evidência na seguinte tradução, que melhor explicita o questionamento como convívio e empenho conjunto em torno a questões: "Aquilo que está em questão para a filosofia não é dizível, isto é, passível de ser discutido, como as outras coisas que podemos aprender, mas é algo que aconteceu e acontece na alma, e, com efeito, em razão e por meio de uma comunhão autêntica, de um autêntico ser-um-com-o-outro junto à coisa mesma, é algo que cresce a partir de um empenhar-se-um-com-os-outros em torno da coisa mesma" (Heidegger, 2008b, p. 236). E, em seguida, acrescenta Heidegger: "Quando esse empenhar-se-um-com-os-outros em torno da coisa mesma acontece, então acontece também o filosofar, subitamente como um fogo que salta de um ponto para outro, de modo que a fagulha saltitante traz a claridade e a luz no interior das quais o ser se torna visível" (p. 236).
} 
Não obstante, cada qual, porém, está ao seu modo no percurso deste questionamento, a ponto tal que, tantas vezes, é até dado e exigido a um pensador singular se posicionar contra todos os outros. Todavia, este posicionamento não aniquila ou nega a originária convivência no inter-médio das questões. Ao contrário, solicita este estar-um-junto-com-o-outro, pois a singularidade de cada posição é, na verdade, o sinal de uma comum-pertinência à mesma questão, ao único e necessário a ser questionado (Heidegger, 2010). O único não equivale ao igual. Antes, é fonte da diversidade, prévia unidade de reunião do plural. No entanto, frequentá-lo longamente, num empenho conjunto, na recepção cordial aos apelos da única coisa a ser questionada, é condição sine qua non para que, de chofre, se acenda e se mantenha acesa uma possibilidade singular da busca que é o questionamento.

Conviver com este único, constituindo uma comunidade de questionamento entre aprendiz e mestre, certamente é umas das principais tarefas do ensino da Filosofia, se não a primordial. Nesta autêntica comunidade abre-se também o horizonte da aprendizagem para aquele que se introduz na arte do pensar, assumindo como obra da conquista de uma posição singular neste ser-um-com-o-outro junto à coisa mesma do pensar. E se, no seu fundamento, esta aprendizagem é convivência dialogal no intermédio da questão, por certo, toda concreção deste originário diálogo, por exemplo, um curso de formação em Filosofia, ainda é uma impossibilidade possível. Pois a impossibilidade de ensinar filosofia, na verdade, é possibilidade de tomar parte, de modo decisivo e único, em um acontecimento histórico, muito maior que o da história pessoal ou pretensões individuais. Certamente por isto, o pensamento não nasce, assim, de modo fortuito, esporádico, voluntarioso de uma pretensão isolada, nem de um cálculo teórico- metodológico, mas da profundeza de uma raiz comum, como adverte Nietzsche (1998):

Não temos o direito de atuar isoladamente em nada: não podemos errar isolados, nem isolados encontrar a verdade. Mas sim, como necessidade com que uma árvore tem seus frutos, nascem em nós nossas ideias, nossos valores, nossos sins e ses e quês - todos relacionados e relativos uns aos outros, e testemunhas de uma vontade, uma saúde, um terreno, um sol. (p. 8)

Estranho este modo peculiar de questionar do pensamento. Mesmo sendo única a sua questão, esta especificidade conduz à impossibilidade de adotar um modelo padronizado de questionamento, objetivo, não obstante, tantas vezes assumido sem mais de outrem e impessoalmente reproduzido. Questioná-la é sempre um feito singular. E, todavia, não nenhum fato isolado, de tal modo que, quanto mais crítico e autônomo for o ensino-aprendizagem do filosofar, tanto mais se descobre pertencente a uma busca comum: plantado no mesmo solo e iluminado por único sol. Como, porém, se faz tal aprendizagem e se descobre pertencente a uma longa história?

\section{IMPOSSIBILIDADE E RESPONSABI-} L I D A D E

A impossibilidade de ensinar filosofia se revela com maior claridade, tanto mais se apreende o modo específico pelo qual o filosofar se determina como um questionamento totalmente peculiar, aliás, como possibilidade de corresponder à questão em um empenho conjunto e histórico. Todo o filosofar é questionar, mas nem todo o questionamento é um filosofar. A ciência, por exemplo, enquanto modalidade rigorosa de investigação, é uma paixão por questionar. No entanto, as ciências positivas são um questionamento 
sedento por respostas que permitam realizar uma tarefa bastante determinada: constituir permanentemente um sistema de proposições válidas sobre o real (Heidegger, 2006). Incessantemente, as ciências questionam para fazer crescer este sistema, com o propósito e expectativa de que se esclareça objetivamente e, com isto, seja demarcado, sempre mais precisamente, o âmbito que possibilite desvelar o ente questionado. Assim, as ciências projetam ter para si o seu respectivo questionado como algo já encontrável segundo uma orientação antecipadora, isto é, segundo o positum de cada ciência (Heidegger, 2008b). O questionamento científico, então, é uma postura diante do real internamente orientada pela tendência de cumprir-se como a busca que, desde o ponto de partida, nada procura ao léu ou às cegas. Antes, a busca é movida pela espera que a visão de seu âmbito de procura, previamente aberto, se determine como um horizonte sempre mais nítido. É particular às ciências ver por antecipação o que procuram ou questionam e seu "mérito" é estarem orientadas para vê-lo com a maior acuidade possível; porém, sem abandonar seu horizonte previamente delimitado de visão.

Em virtude desta tendência teóricooperativa, o questionamento científico é, por assim dizer, uma avidez por resultados. Por isso, a ciência é a busca que sempre volta sobre si, como uma reação às obscuridades nas vias da experimentação, para verificar a adequação ou a inadequação de seu projeto antecipador de manifestação do real (Rombach, 1988). Por conseguinte, o resultado procurado não é tanto uma aplicação do conhecimento, não é primariamente a proposição válida. Pelo contrário, é a clarificação da visão de seu âmbito de procura, para que este revele, de fato, o ente questionado segundo o interesse de questionamento particular de cada ciência. Deste modo, por um lado, o questionamento científico é primorosa busca de rigor; é incansável procura por demonstrar, justificar e comprovar os princípios que delimitam, com precisão, o âmbito predefinido de visão que, do início ao fim, o delimita e o caracteriza como especializada interrogação de dado setor do real ou região do ente.

Por outro lado, de resultado em resultado, de clareza em clareza, necessárias para enriquecer o tesouro de verdades válidas de dado sistema de proposições objetivas, é justamente aquela postura que permanece inquestionada na sua própria origem e na sua tendência interna de busca da verdade. Em tanto esforço por aprimorar a perspectiva pela qual cada ciência visa e questiona o seu questionado, esquece-se de questionar a própria possibilidade da visão: ser e ver são, aqui, ontologicamente o mesmo. Assim, passa-se ao largo do fato de que essa impostação diante do real é uma possibilidade de ser daquele ente que questiona, de ser e se transformar nele mesmo. Não se questiona o ente que interroga (Heidegger, 2006), o ser humano em seu modo próprio de ser, nem se há uma íntima correlação entre a determinação do ser de quem questiona e o projeto de manifestação do ser dos entes questionados. E mais: não se interroga radicalmente se a ciência, enquanto possibilidade do humano se perfazer como interrogador, e a pretensão nela inerente de impor-se como a via exclusiva de determinação do ente questionado, permitem ao ser humano desbravar o caminho de originária realização de si mesmo. Tudo isto se oculta na avidez com que se corresponde à tendência interna da ciência por resultados.

Em razão deste ocultamento, nas ciências positivas, o rigor não ultrapassa os limites da tarefa de definir as retas condições da possibilidade de desvelamento do ente, o que se traduz no problema se o que se anteviu sobre o questionado foi expressa e devidamente concebido. Assim, é o rigor na colocação de 
certo problema, porém, na expectativa de que a clarificação da visão, por meio do aclaramento da perspectiva prévia, os problemas sejam superados e o conhecimento seja lançado para outros novos. E se, na realização da tendência interna das ciências, se dá o encontro com a impossibilidade, esta possui o caráter de uma inadequação, que exige o contínuo passo atrás nas predefinições do âmbito de visão e a clarificação dos pressupostos teóricos, até ao ponto em que as sombras das dúvidas se dissipem e as certezas sejam (re) asseguradas, em um processo interminável de colocação e superação dos problemas. Assim, as impossibilidades revelam-se como dignos problemas; porém, na perspectiva da potenciação do projeto prévio de manifestação do real, cada um deles é apenas um degrau na posse cada vez mais certa da verdade.

Chamamos este modo específico das ciências questionarem de problematização. Em rigor, o filosofar não problematiza. Como, porém? No ensino-aprendizagem da Filosofia, o grande esforço não é aprender a problematizar com rigor e argumentar com precisão lógica? Nos cursos de Filosofia, não se dá grande relevo a esta aprendizagem? Com certeza! Esta constatação óbvia, porém, nada diz sobre a essência do questionar filosófico. É que o filosofar não é nenhuma inspeção teorética sobre as coisas e sobre o humano e, por isso, primariamente, não é orientado para a colocação de problemas. Antes, o filosofar é endereçado à própria existência de quem questiona, mas de tal modo que é o ser humano mesmo que é colocado pela questão questionada, no sentido em que ele mesmo é forjado por ela, no seu próprio ser, à medida que procura pelo sentido próprio de ser ele mesmo. Nesta perspectiva, o questionamento filosófico é também um passo para trás, em direção ao ente que questiona, mas as respostas encontradas não são resultados que fornecem a base para outras respostas ulteriores, que cresceriam em exatidão e objetividade, conforme uma escala progressiva de conhecimentos. Na verdade, as respostas desaparecem, porque cada resposta não faz mais que aumentar a questionabilidade do que se questiona (Heidegger, 2006). O que está em questão, em primeiro plano, não é determinar um ente qualquer ou uma de suas propriedades - no caso do ser humano, não se pergunta o que ele tem, mas o que ele é (Rombach, 1988). Permanece, assim, somente a questão, mas como um caminho que se aprofunda, pois o que se perscruta, cada vez mais e numa crescente e misteriosa obscuridade, é o modo de ser daquele ou daquilo que se questiona.

Neste sentido, o questionar filosófico, muito mais que uma tendência em progredir no acúmulo das verdades, é uma disposição de permanecer, longamente, junto ao que se deve questionar. Pouco a pouco, esta frequentação demorada junto à questão pode conduzir o ser humano para aquilo que é: o único ente capaz de questionar. Mas esta capacidade não só diz que o ser humano está em condições de em tudo colher o sentido do ser, na unidade e na diferença das múltiplas concreções dos entes. Deve-se enfatizar que ele não possui esta capacidade como propriedade, de tomar posse, no sentido usual de apoderarse de algo, mas sim que é ela que o constitui essencialmente; esta capacidade o tem, pois nela o humano se realiza de um modo que não se iguala a nenhum outro ente, nem mesmo a outro ente humano. Esta capacidade, portanto, é propriedade no sentido originário, a saber, aquilo que o conduz para a verdade de seu ser, para o seu ser-próprio. Assim, ser capaz do questionamento diz, sobretudo, que ele é o único ente que está sempre colocado em uma pergunta, a questão do seu ser. Radicalmente, esta questão coloca o ser humano em si mesmo, em vez de simplesmente colocar problemas ao 
se posicionar como o sujeito de conhecimento. Então, este colocar-se na questão toca-o em toda a sua existência; instalar-se nela é o modo de ser ele mesmo. Aqui, não se tem perguntasproblemas, mas é-se a pergunta nascida pelo fato de ser uma questão para si mesmo.

Chamamos, com Rombach (1988), este modo de questionamento de decisão. Ele é a tarefa de fazer a experiência de tornar-se próprio no modo de ser humano; é a exigência de ter que apropriar-se deste modo de ser em seu todo e em particular, portanto, numa direção una, porém, em duplo aspecto: universalizando-se $e$ singularizando-se. Como tal, este modo de questionar solicita a cada ser humano decidir ser ele mesmo e se cindir dos demais entes (no sentido de diferenciar-se, individuar-se) e de um agir interrogativo que seja somente operação, ocupação com problemas. Nele, a questão clama pela responsabilização por si, não meramente por isto ou por aquilo, colocando as razões do questionar nas coisas, nas circunstâncias ou nas outras pessoas. Deste modo, é o questionamento que possui a si por meta, isto é, visa ser só a busca que ele é, porque é a resolução decidida do ser humano tornar a si mesmo. Tanto, pois, o seu fundamento ou motivo, assim como qualquer resposta que dele advenha, não pode ser senão esta decisão de singularizar-se. Decide tornar-se ele mesmo, porém, para realizar-se ou inserir-se de modo mais próprio neste questionamento, sem querer aniquilar, em qualquer momento, a ação interrogativa e o imperativo da decisão. $\mathrm{Na}$ contínua busca e responsabilização por si mesmo, o questionamento é pleno. Assim, qualquer resposta não depõe o caráter de questão de ser, para si, um mistério, uma pergunta. Sendo tão fundamental, ela só perdura em seu próprio questionamento, na ação mesma de interrogar(-se), já que é existência humana como tal, se consumando essencialmente, perfazendo-se como uma tarefa singular. Porém, nisto, gera uma originária comum-unidade com todos os seres humanos.

Trata-se, pois, de um modo de indagar que, estranhamente, não exige nenhum prérequisito, nenhum conhecimento prévio, nenhuma informação ou instrução alheia. Todavia, isto não quer dizer que a indagação seja fruto do arbítrio pessoal ou do querer voluntarioso, subjetivo-individualista. Como atinge a existência no todo de cada ser humano em particular, cada singular, desde que exista, já está colocado neste questionar. Por isto, sua questão não tolera nenhuma escolha de colocála ou não, bem como de adiá-la ou assumila quando oportuno. A todo o momento, assumindo-o ou não de modo autônomo e responsável, postergando-a, delegando-a, interpretando-a como uma teoria qualquer ou algo que esteja a bel-prazer do sujeito, cada ser humano, de algum modo ou outro, já se responsabilizou de modo bastante singular por este questionamento. Aliás, responsabilizarse ou não são modos de decisão, embora no segundo modo o ser humano dê uma resposta deficiente ao apelo inscrito em seu ser de conquistar-se a si mesmo. Assim, cada ser humano mostra quem é na resposta que, a cada instante, irremissivelmente dá à sua indagação. Isto quer dizer, então, que, na tarefa de revelação de si mesmo, este peculiar questionamento está continuamente em ação na existência de todo o ser humano, mesmo que este não tenha dele tomado conhecimento, de modo explícito ou temático, por si ou mediante outrem ou por ter-se informado de uma teoria a respeito.

Ora, um questionamento desta modalidade é impossível de ser ensinado, pois não se constitui, fundamentalmente, como teoria, mas como responsabilização de liberação de si mesmo; não possui conteúdo, senão o fruto maduro da decisão que vem à luz e em tempo 
oportuno na obra de singularização de cada existente; não possui forma, senão o modo pelo qual o ser humano decide seu próprio ser. Por outro lado, ninguém se decide a partir do nada, mas sempre do que já sabe de si, na sua relação com os outros e com as coisas. Quem decide, o faz para saber mais perfeitamente sobre si e, no questionar o já sabido acerca de si mesmo, trazer à luz seu ser de modo mais próprio. $\mathrm{O}$ verdadeiro aprendizado, então, pressupõe certa compreensão acerca de si, mas também um querer saber mais radicalmente, ir mais fundo no que se sabe. O questionamento como decisão revela, de modo extremo, este caráter do aprender, pois, nele, cresce nada menos que o saber de como é possível o ser humano, isto é, de como ele pode dar a si para si mesmo, a partir do que compreende dele mesmo. Mas dado que, neste compreender, o ser humano, na maior parte das vezes, vigora em um esquecimento de seu ser-próprio, tão extremo é este questionar que nele também pode se perder de si mesmo; também nele medra uma compreensão vaga e imprópria, na qual o ser humano desaprende quem é. Extremo, porém, é aquilo que é fundamental. Por isto, este questionamento está em jogo em todo o aprender e ensinar, onde quer que seja e mediante todas as possibilidades de que o ser humano dispõe para produzirse a si mesmo, isto é, revelar-se no seu serpróprio, historicamente e singularmente. Ele é o experimentar aquilo que já se tem, dando-o para si mesmo:

A este aprender corresponde, também, o ensinar. Ensinar é um dar, um oferecer; no ensinar, não é oferecido o ensinável, mas é dada somente ao aluno a indicação de ele próprio tomar o que já tem. Quando o aluno recebe apenas qualquer coisa de oferecido, não aprende. Aprende, pela primeira vez, quando experimenta aquilo que toma como sendo o que, verdadeiramente, já tem. O verdadeiro aprender está, pela primeira vez, onde o tomar aquilo que já se tem é um dar a si mesmo e é experimentado como tal. Por isso, ensinar não significa senão deixar os outros aprender, quer dizer conduzir mútuo até a aprendizagem. (Heidegger, 1992b, p. 79)

Nesta direção, seriam necessárias várias observações conclusivas. Fazemos somente algumas, porém, sem desenvolvê-las. Primeiramente, por graças da radicalidade deste questionamento, ensinar e aprender não têm a ver, primariamente, com métodos e transmissão de teoria, mas sim com a mediação de uma experiência única e diversa, que é a de tomar posse de si mesmo, apropriar-se, numa ação mútua entre os seres humanos e no confronto com os saberes e as coisas. Em segundo lugar, se aprender-ensinar é a coisa mesma da educação, então, neste questionamento radical e decisivo deve se assentar o ato educativo, pois, como já revela a etimologia da palavra educo, educare, educação é arte de revelação do humano no seu ser, trazendo-o para "fora", à medida que o conduz de si mesmo para si mesmo, na autonomia da responsabilização acima acenada. Para isto, não se poderá partir senão do saber que sabe de si junto às coisas, por mais indeterminado e impreciso que seja; porém, na disposição de assumi-lo de modo mais límpido e originário. Em terceiro lugar, em decorrência das observações anteriores, é admissível que a filosofia ainda possa ser uma disciplina escolar; porém, como lugar da aprendizagem da responsabilização por saber o que se sabe, questionando o sentido de ser si mesmo cada vez decisivamente, como também das coisas que rodeiam o ser humano e os fatos, em relação aos quais também a busca decisiva de si está implicada.

Outrossim, é preciso dizer que as considerações anteriores refletem a indissociabilidade entre o ensinar filosofia e o 
aprender a pensar, caminho único que docentes e discentes percorrem à medida em que se empenham no questionamento do sabido, em vista de saber mais radicalmente o óbvio e evidente. Caminho, porém, que toma rumo para o não-sabido, ao não poder assegurarse do que se sabe. Assim, não se propôs outra coisa - que a única possibilidade de ensinaraprender filosofia é o caminho da experiência do pensar. Uma vez que esta experiência é a do questionamento enquanto a constituição do ser humano na via de sua singularização, nada neste ensino-aprendizagem pode ser dado e ofertado de antemão. A assunção do pensar como o horizonte ainda possível do ensino da filosofia é, portanto, também de sua impossibilidade. No cotidiano das instituições de ensino, impõe-se ainda mais a necessidade do ensino da filosofia, de sua democratização, inclusive opondo-a às modalidades historiográficas e acepções tecno-científicas do saber. Uma necessidade irrevogável e premente. Na voga destes discursos, porém, a filosofia tantas vezes sucumbe aos atuais ditames da produção, guiados pela ideia de progresso, da renovação incessante e turbulenta do conhecimento. Assim, na pedagogização do filosofar, em muitas direções e formas, na mão e contramão do império das técnicas de produção do conhecimento, nos arranjos e desarranjos das disciplinaridades, das interdisciplinaridades, encontra-se silenciada a impossibilidade de ensinar filosofia. Também quando se apregoa a necessidade de aprender a pensar. Deste modo, diante da atual supervalorização da filosofia e seu ensino (por exemplo, na constituição do sujeito crítico e agenciador das transformações dos processos sociais), assim como da sua subestimação, quando se reduz o pensamento a um inócuo objeto de conhecimento e ensino, à guisa de conclusão e provocação ao pensar, recorda-se outra fala zombeteira contra o projeto moderno de viver e tudo valorar a partir da ciência, inclusive o filosofar:

Não quero converter ninguém à filosofia: é necessário, é talvez também desejável, que o filósofo seja uma planta rara. Nada me é mais repugnante que a propaganda doutrinal da filosofia (...). Filosofia tem pouco a ver com a virtude. Que me seja permitido dizer: também o homem científico é algo fundamentalmente diferente do filósofo - O que desejo é que [...] o autêntico conceito de filósofo não sucumba totalmente. (Nietzsche, 2008, p. 222)

Apesar de todo o agenciamento da filosofia sem muito cuidado com o pensamento, podemos ainda crer que, no tempo presente, ensinar filosofia é uma impossibilidade ainda possível?

\section{REFERENCIAS}

Agostinho. (2002). Confissões. Petrópolis: Vozes.

Aristóteles. (2002). Metafísica. São Paulo: Loyola.

Heidegger, M. (1972). Uma carta. In M. Heidegger, O fim da filosofia ou a questão do pensamento (pp. 13-19). Rio de Janeiro: Duas Cidades.

Heidegger, M. (1992a). "Probleme" der "Logik" [Questões básicas de Filosofia. "Problemas selecionados da "lógica"]. Frankfurt am Main: Vittorio Klostermann.

Heidegger, M. (1992b). Que é uma coisa? Doutrina de Kant dos princípios transcendentais. Lisboa: Edições 70.

Heidegger, M. (1999a). Introdução à metafísica. Rio de Janeiro: Tempo Brasileiro.

Heidegger, M. (1999b). Que é isto - A filosofia?. In M. Heidegger, Conferências e escritos filosóficos (pp. 23-40). São Paulo: Nova Cultural.

Heidegger, M. (2000). Ser e tempo. Petrópolis: Vozes. 
Heidegger, M. (2006). Einführung in die phänomenologische Forschung [Introdução à pesquisa fenomenológica]. Frankfurt am Main: Vittorio Klostermann.

Heidegger, M. (2008a). Carta sobre o humanismo. In M. Heidegger, Marcas do caminho (pp. 326-376). Petrópolis: Vozes.

Heidegger, M. (2008b). Introdução à filosofia. São Paulo: Martins Fontes.

Heidegger, M. (2010). Meditação. Petrópolis: Vozes.

Nietzsche, F. (1998). Genealogia da moral. Uma polêmica. São Paulo: Companhia das Letras.

Nietzsche, F. (2008). Vontade de poder. Rio de Janeiro: Contraponto.

Pascal, B. (2005). Pensamentos. São Paulo: Martins Fontes.

Platão. (1999). Fédon. In Platão (pp. 115-190). São Paulo: Nova Cultural.

Platão. (2011). Cartas e epigramas. São Paulo: Edipro.

Platone. (2005). Le opere. Roma: Newton \& Compton.

Rombach, H. (1988). Über ursprung und wesen der frage [Sobre a origem e essência da questão]. Freiburg/München: Karl Alber.

Sófocles. (2004). A triologia tebana. Rio de Janeiro: Jorge Zahar.
LEARNING TO THINK AND THE IMPOSSIBILITY TO TEACH PHILOSOPHY

\section{Abstract}

In a phenomenological approach, this article reflects the teaching of philosophy, assuming it as a possibility to the experience of learning to think. In this way, the study aims to show that the understanding of this possibility lies in an impossibility which is ontological in character, since learning to think cannot be offered or made possible by others. Such impossibility goes back to the essence of human singularity. In this horizon, the (im)possibility to learn to think is based on philosophical questioning, however, understood as the responsibility of the human being to decide and appropriate his or her original way of being. In order to demonstrate this foundation, the study starts from the ontological sense of impossibility of human existence, defining it as remission and a leap to the possible, in this case, to be able to think and question. Next, the questioning and its historical character are clarified, differentiating it from the method of problematization of the positive sciences. Thus, we arrive at a critical position of the tendencies in which the teaching of philosophy is understood from the goals and the techno-scientific methods, as well as the pedagogization of the philosophical one, and also of its bureaucratization in view of its structuring to the mechanisms of producing scientific knowledge with its current requirements.

KEYWORDS: Thought; Questioning; Science and technique; Philosophy teaching; Pedagogization 


\section{EL APRENDIZAJE DEL PENSAR Y LA IMPOSIBILIDAD DE ENSENAR F I L O S O F Í A}

\section{RESUMEN}

En un enfoque fenomenológico, el artículo refleja la enseñanza de la Filosofía, asumiéndola como posible en cuanto experiencia del aprendizaje del pensar. En esta dirección, el estudio tiene por meta mostrar que la comprensión de esta posibilidad radica en una imposibilidad de carácter ontológico, en cuanto el aprender a pensar no puede ser ofrecido o posibilitado por otro. Esta imposibilidad es reconducida para el modo de constitución de la singularidad humana. En este horizonte, la (im)posibilidad de aprender a pensar se funda en el cuestionamiento filosófico, sin embargo, entendido como responsabilidad del ser humano por decidirse y apropiarse de su originario modo de ser. Para demostrar esta fundamentación, el estudio parte del sentido ontológico de imposibilidad para el existir humano, definiéndolo como remisión y salto hacia lo posible, en el caso, para el ser capaz del pensar y cuestionar. A continuación, se aclara el cuestionamiento y su carácter histórico, diferenciándolo del método de problematización de las ciencias positivas. Así, se llega a un posicionamiento crítico a las tendencias en que se comprende la enseñanza de la filosofía a partir de las metas y de los métodos tecno-científicos, así como de la pedagogización del filosofar $y$, además, de su burocratización en vista de su marco a los mecanismos institucionales de producción del conocimiento científico con sus actuales exigencias.

Palabras Clave: Pensamiento; Cuestionamiento; Ciencia y técnica; Enseñanza de filosofía; Pedagogización

\footnotetext{
I Centro de Formação de Professores (CFP), Colegiado do Curso de Filosofia, Universidade Federal do Recôncavo da Bahia / UFRB. Orcid: 0000-0001-6059-4400
}

Toda a correspondência relativa a este artigo deve ser enviada para:

Daniel Rodrigues Ramos

Centro de Formação de Professores (CFP), Colegiado do Curso de Filosofia,

Universidade Federal do Recôncavo da Bahia / UFRB

Avenida Nestor de Mello Pita, No 535, Caixa Postal 64, Centro - Amargosa,

Bahia - Brasil, 45.300-000

Recebido em março de 2018

E-mail: dr.ramos@ufrb.edu.br 